\title{
Transcapillary colloid osmotic gradient, plasma volume and interstitial fluid volume in long-term Type 1 (insulin-dependent) diabetes
}

\author{
P. Fauchald ${ }^{1}$, J. Norseth $^{2}$ and J.Jervell ${ }^{1}$ \\ Medical Department $B^{\hat{\imath}}$ and Department of Clinical Chemistry ${ }^{2}$, National Hospital, Rikshospitalet, Oslo, Norway
}

\begin{abstract}
Summary. Plasma and subcutaneous colloid osmotic pressure, transcapillary escape rate of albumin, plasma volume and extracellular fluid volume were measured in 10 long-term Type 1 (insulin-dependent) diabetic patients without clinical nephropathy. Interstitial colloid osmotic pressure was reduced compared with normal subjects $(12.9 \pm 3.0$ versus $15.8 \pm$ $2.7 \mathrm{mmHg}, p<0.05)$ and the transcapillary colloid osmotic gradient increased $(17.0 \pm 2.4$ versus $12.8 \pm 2.7 \mathrm{mmHg}, p<$ $0.01)$. Plasma volume was in the normal range and interstitial fluid volume increased by approximately $21 \%$ compared with normal subjects $(p<0.01)$. Transcapillary escape rate of albumin was significantly increased compared with normal sub-
\end{abstract}

jects $(8.9 \pm 1.9$ versus $5.1 \pm 1.6 \% / \mathrm{h}, p<0.01)$. A negative correlation was found between the transcapillary colloid osmotic gradient and interstitial fluid volume $(r=0.6,0.01<p<0.05)$. These results suggest that the increased small vessel permeability in long-term diabetes leads to wash-out of interstitial proteins and the resulting increased transcapillary colloid osmotic gradient tends to preserve the plasma volume and to limit the tendency to increased interstitial fluid volume.

Key words: Type 1 diabetes, interstitial colloid osmotic pressure, plasma colloid osmotic pressure, interstitial fluid volume, plasma volume, transcapillary escape rate of albumin.
Increased microvascular permeability to small [1-3] and large molecules $[4,5]$ is found in patients with long-term diabetes. This increased small vessel permeability can be demonstrated in various tissues and organs $[3,6,7]$. The findings of Alpert et al. [8] of increased capillary diffusion capacity and no significant change in capillary filtration coefficient measured in leg muscles in long-term diabetes suggest that small vessels are abnormally permeable to small molecules and that the increased diffusion capacity is not due to increased surface area of the microvasculature. Poulsen and Nielsen, however, found significantly increased capillary filtration coefficient measured in the forearm [9].

The distribution of fluid between the blood and the extravascular space is usually assumed to be determined according to Starling's hypothesis concerning fluid transfer. The disturbances in capillary permeability to proteins, as well as to small molecules in diabetic patients, could lead to changes in the transcapillary colloid osmotic gradient and to the distribution of the extracellular fluid. The aim of the present study was to evaluate the relationships between the transcapillary colloid osmotic gradient, plasma and interstitial fluid volume and the transcapillary escape rate of albumin in patients with long-term Type 1 diabetes.

\section{Subjects and methods}

\section{Subjects}

Ten Type 1 diabetic patients (seven females, three males, mean age 37 years) were studied. Age, duration of diabetes and clinical details are given in Table 1 . Their mean height was $169 \pm 8.4 \mathrm{~cm}$ and their mean body weight was $64.5 \pm 7.9 \mathrm{~kg}$. All patients had Albustix-negative urine. None were on anti-hypertensive drugs or diuretics and all were normotensive (blood pressure $<145 / 90 \mathrm{mmHg}$ ). Patient 1 was unable to collect $24 \mathrm{~h}$ urine reliably. Her urine was Albustix-negative and she had normal serum creatinine $(85 \mu \mathrm{mol} / 1)$. All patients were treated by twice daily injections of insulin (Monotard, Rapitard, Actrapid, Novo Industries, Copenhagen, Denmark; Insulatard, Velosulin, Nordisk, Gentofte, Denmark) (Table 1) and none had ketosis at the time of investigation. Five had retinopathy; in three this was proliferative. They were all ambulant in full-time employment. None had symptoms or signs of heart or liver disease and clinical examination revealed no oedema.

Plasma and extracellular fluid volumes and transcapillary escape rate of albumin were measured in the morning after an overnight fast, in the supine position and before injection of insulin. The patients were recumbent for at least $30 \mathrm{~min}$ before the tracer injections were given. After breakfast and their usual insulin dose, measurements of plasma and interstitial colloid osmotic pressure were performed with the patients in the supine position.

\section{Normal subjects}

Colloid osmotic pressure in plasma and interstitial fluid was measured in 16 normal subjects ( 4 females, 12 males). Their age ranged 
Table 1. Clinical characteristics and laboratory measurements of the diabetic patients studied

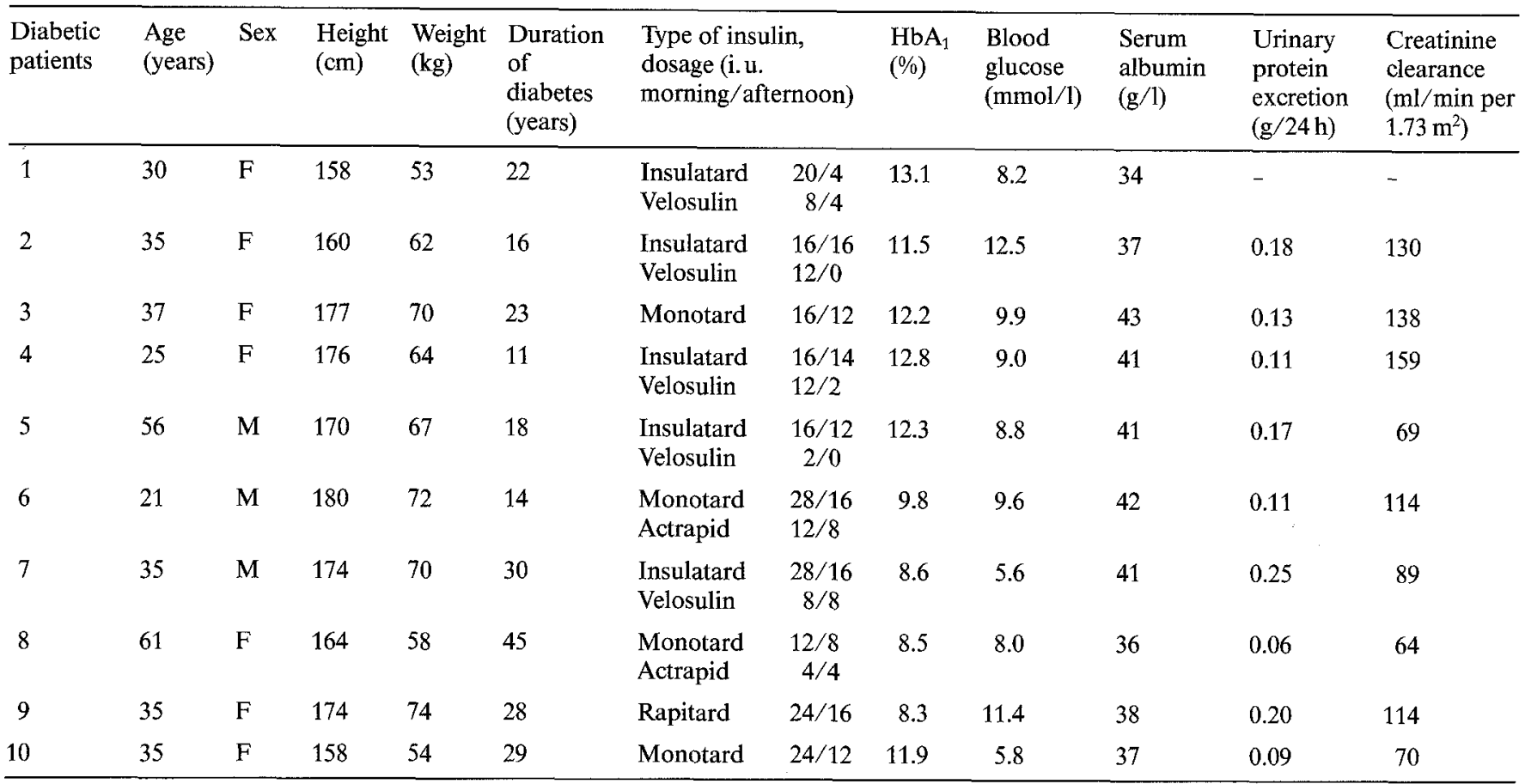

Blood glucose was measured in non-fasting conditions at the time of the investigations

from 33 to 72 years (mean 51 years). All were normotensive (blood pressure $<145 / 90 \mathrm{mmHg}$ ) and had normal serum albumin levels (mean $41.7 \pm 3.4 \mathrm{~g} / \mathrm{l}$, range $35-48 \mathrm{~g} / \mathrm{l}$ ). Measurements were made in the recumbent position and at the same times of the day as in the diabetic patients. Plasma and extracellular fluid volume and transcapillary escape rate of albumin were measured in another group of 19 normal subject (11 females, eight males), aged 22-54 years (mean 36 years). Their mean height was $172 \pm 9.2 \mathrm{~cm}$ and mean body weight $65.9 \pm 11.1 \mathrm{~kg}$. Measurements were made after an overnight fast in the morning with the subjects recumbent for at least $30 \mathrm{~min}$ before the start of the experiments. Urine analysis was normal in all the normal subjects in both groups and also they had normal serum creatinine levels and no symptoms or signs of heart or liver disease.

Informed consent was obtained from all subjects. The protocol was approved by the Ethical Committee, Norwegian Council for Science and the Humanities.

\section{Methods}

Colloid osmotic pressure. A colloid osmometer (Department of Physiology, University of Bergen) made for $5 \mu$ l samples was used [10]. The coefficient of variation within assays was $4.3 \%(n=12)$ and between assays was $4.9 \%(n=10)$. Plasma samples were obtained by venepuncture using short-term stasis.

Interstitial colloid osmotic pressure. Interstitial fluid was collected by the wick technique [11-13]. Under aseptic conditions four double nylon wicks (containing 600 filaments, diameter $1 \mathrm{~mm}$ ) soaked in saline $(0.154 \mathrm{~mol} / \mathrm{l})$ were sewn into subcutaneous tissue on the side of the thorax in a length of $5-8 \mathrm{~cm}$. The skin was anaesthetized by intradermal injection of $0.1-0.2 \mathrm{ml}$ of lidocaine $(20 \mathrm{mg} / \mathrm{ml})$ at the site of the entrance and exit of the wicks. Straight needles $(75 \mathrm{~mm}$ long) without cutting edges were used for implantation (Acufirm, Dreieich, Hessen FRG). After $1 \mathrm{~h}$ implantation, the wicks were removed and transferred immediately to a $10 \mathrm{ml}$ plastic tube containing $8 \mathrm{ml}$ of mineral oil (Paraffin dickflüssig, 7160, Merck, Darmstadt, FRG). Only unstained or slightly pink wicks were accepted, red wicks being excluded. Wick fluid was isolated by centrifugation ( $1000 \mathrm{~g}$ for $15 \mathrm{~min}$ ) under mineral oil [12] and colloid osmotic pressure measured by the colloid osmometer. All the interstitial fluid pressure values in this study represent the mean of at least two (two to four) separate measurements of wick fluid from two to four wicks.

Plasma volume. Plasma volume was determined as the initial ${ }^{125} \mathrm{I}$-albumin distribution space. ${ }^{125} \mathrm{I}$-labelled human serum albumin $(4 \mu \mathrm{Ci}$ Amersham International, Amersham Bucks, UK) was injected intravenously and blood samples were taken after 15 and $30 \mathrm{~min}$. The distribution space was calculated by dividing the injected amount of tracer into the calculated zero-time concentration. Zero-time concentration was calculated from the plasma disappearance curve using the sum of the least square method [14]. Values are given $\mathrm{as} \mathrm{ml} / \mathrm{cm}$ body height.

Extracellular fluid volume. Extracellular fluid volume was measured by administration of intravenous radiosulphate as by Walser et al. [15] but modified by McGrath et al. [16]. Approximately $25 \mu \mathrm{Ci}$ in a volume of $5 \mathrm{ml}$ of $\mathrm{Na}_{2}{ }^{35} \mathrm{SO}_{4}$ (Amersham International) was injected intravenously. Blood samples were drawn from the contralateral arm at 30 and $60 \mathrm{~min}$ after injection, and plasma was obtained by centrifugation at $2000 \mathrm{rpm}$ for $10 \mathrm{~min}$. Proteins were precipitated by adding trichloracetic acid $(30 \%, 1 \mathrm{ml})$. The administered dose of radiosulphate was calculated from standards prepared for counting the same way as the blood samples to reduce the problem of quenching in the plasma samples compared to the standards. The radiosulphate space $(\mathrm{S}, \mathrm{lit})$ was calculated from the following fomula:

$\mathrm{S}=\frac{\mathrm{C}_{\mathrm{i}} 0.91}{\mathrm{~T}_{\mathrm{o}}}$

where $C_{i}$ equals the total number of $\mathrm{cpm}$ injected, 0.91 is a fraction to correct for the Gibbs-Donnan effect [17] and $T_{0}$ is the calculated zero time concentration. The zero time concentration of radiosulphate was calculated by means of sample counts using the sum of the least square method [14]. The values are given as percentage body weight.

Interstitial fluid volume. Interstitial fluid volume equals extracellular fluid volume minus plasma volume and the values are given as percentage body weight. 
Transcapillary escape rate of albumin. The transcapillary escape rate of albumin $\left(\mathrm{TER}_{\mathrm{alb}} \% / \mathrm{h}\right)$ was determined from the initial disappearance rate of ${ }^{125} \mathrm{I}$-albumin $[4,5,18,19]$. The disappearance of ${ }^{125} \mathrm{I}$-albumin was assumed to be a monoexponential function during the first $30 \mathrm{~min}$ after injection. $\mathrm{TER}_{\mathrm{alb}}$ was calculated as the disappearance rate constant by the least square method [14].

$\mathrm{HbA}_{1}$, was measured using agar gel electrophoresis (Corning). The normal range is $5.0-7.5 \%$.

\section{Statistical methods}

Wilcoxon's test for two independent samples was used. Correlations were calculated by least square linear regression analysis. Results are given as mean $\pm S D$.

\section{Results}

\section{Plasma and interstitial colloid osmotic pressure}

Plasma colloid osmotic pressure was in the normal range and similar to the values in normal subjects (Table 2, Fig.1). Mean interstitial colloid osmotic pressure was reduced by approximately $3 \mathrm{mmHg}$ compared to normal subjects $(p<0.05)$. The resulting transcapillary colloid osmotic gradient in the patients was increased by approximately $4 \mathrm{mmHg}(p<0.01)$.

\section{Plasma volume, extracellular fluid volume and interstitial fluid volume}

Plasma volume in the patients was similar to the values in normal subjects (Table 2, Fig.2). In the patients extracellular fluid volume was $20.1 \pm 2.6$ compared with $17.4 \pm 2.2 \%$ body weight in the normal subjects $(p<$ $0.01)$. Mean interstitial fluid volume was in the patients was increased by approximately $21 \%$ compared with normal subjects (Table 2, Fig. 2). As a result, the distribution of fluid between the intravascular and the interstitial space was significantly different in the patients compared with normal subjects $(p<0.01)$.

\section{Transcapillary escape rate of albumin}

The values for $T_{E R} R_{a b}$ were significantly increased in the patients compared to normal subjects $(p<0.01$, Table 2, Fig. 2), but with some overlapping values.

In the patients a negative correlation was found between transcapillary colloid osmotic gradient and interstitial fluid volume $(r=-0.6,0.01<p<0.05)$. No correlation was found between interstitial colloid osmotic pressure and interstitial fluid volume.

\section{Discussion}

Methods for measurement of interstitial colloid osmotic pressure have recently been reviewed by Aukland and Nicolaysen [20]. The wick technique has been extensively investigated in both experimental animals and man
Table 2. Colloid osmotic pressures, body fluid volumes and transcapillary escape rate of albumin in diabetic patients and normal subjects

\begin{tabular}{lll}
\hline & $\begin{array}{l}\text { Diabetic } \\
\text { patients } \\
(n=10)\end{array}$ & $\begin{array}{l}\text { Normal } \\
\text { subjects }\end{array}$ \\
\hline $\begin{array}{l}\text { Plasma colloid } \\
\text { osmotic pressure (mmHg) }\end{array}$ & $29.9 \pm 2.2$ & $\begin{array}{l}28.6 \pm 3.4 \\
(n=16)\end{array}$ \\
$\begin{array}{l}\text { Interstitial colloid } \\
\text { osmotic pressure (mmHg) }\end{array}$ & $12.9 \pm 3.0^{\mathrm{a}}$ & $\begin{array}{l}15.8 \pm 2.7 \\
(n=16)\end{array}$ \\
$\begin{array}{c}\text { Transcapillary colloid } \\
\text { osmotic gradient (mmHg) }\end{array}$ & $17.0 \pm 2.4^{\mathrm{b}}$ & $\begin{array}{l}12.8 \pm 2.7 \\
(n=16)\end{array}$ \\
$\begin{array}{c}\text { Plasma volume (ml/cm) } \\
\text { Interstitial fluid } \\
\text { colume (\% body weight) }\end{array}$ & $17.0 \pm 2.2$ & $\begin{array}{l}17.3 \pm 1.5 \\
(n=19)\end{array}$ \\
$\begin{array}{l}\text { Ratio of plasma volume to } \\
\text { interstitial fluid volume }\end{array}$ & $0.29 \pm 0.05^{\mathrm{b}}$ & $\begin{array}{l}0.36 \pm 0.06 \\
(n=19)\end{array}$ \\
$\begin{array}{c}\text { Transcapillary escape rate } \\
\text { of albumin (\%/h) }\end{array}$ & $8.9 \pm 1.9^{\mathrm{b}}$ & $\begin{array}{c}5.1 \pm 1.6 \\
(n=19)\end{array}$ \\
\hline
\end{tabular}

Results expressed as mean $\pm \mathrm{SD}$

${ }^{\mathrm{a}} p<0.05 ;{ }^{\mathrm{b}} p<0.01$ compared with normal subjects

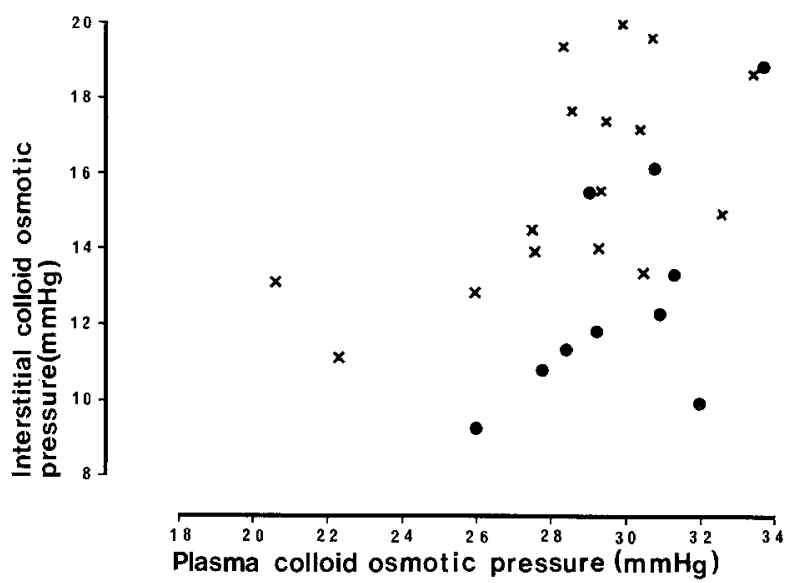

Fig. 1 Plasma colloid osmotic pressure and interstitial fluid colloid osmotic pressure in 10 diabetic patients ( ) and 16 normal subjects $(x)$

by Fadnes and Aukland [21] and Noddeland [13] and the method gives representative and reproducible results. In experimental animals, reduced subcutaneous interstitial colloid osmotic pressure is paralleled by a reduction in colloid osmotic pressure in skeletal muscle interstitial fluid and lymphatic protein concentration [20]. Standard methods were used to measure plasma volume, TER $\mathrm{R}_{\mathrm{alb}}$ and extracellular fluid volume. Parving [19], using ${ }^{125} \mathrm{I}$-albumin to determine plasma volume and $\mathrm{TER}_{\mathrm{alb}}$, found the coefficient of variation to be $1.5 \%$ (plasma volume) and $8.5 \%\left(\mathrm{TER}_{\mathrm{alb}}\right)$. Bauer et al. [22] determined plasma volume and extracellular fluid volume using ${ }^{125} \mathrm{I}$-albumin and radiosulphate and found less than $4 \%$ mean variation for all body fluid measurements. 

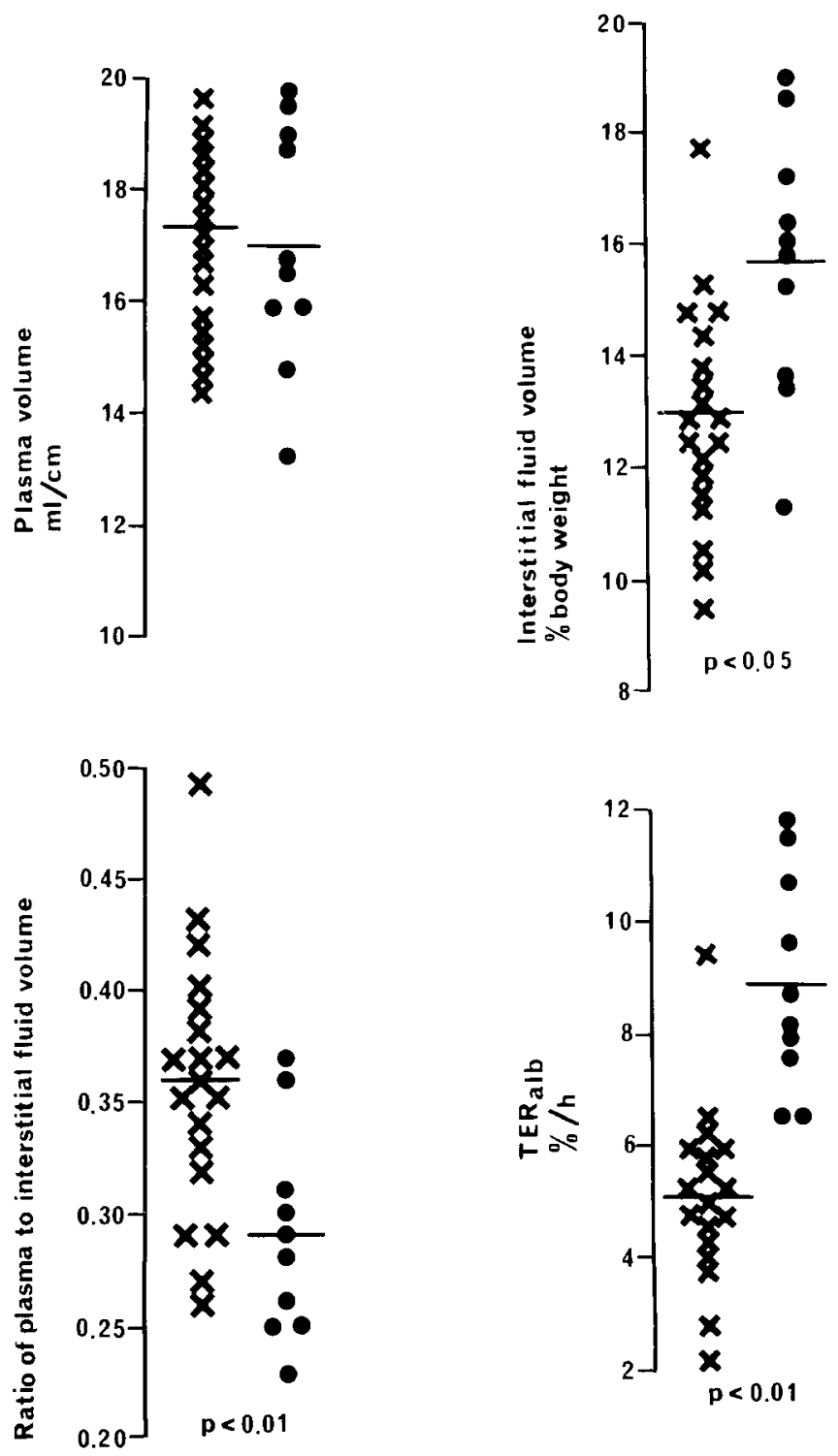

Fig.2. Plasma volume, interstitial fluid volume, the ratio of plasma volume to interstitial fluid volume and transcapillary escape rate of albumin $\left(\mathrm{TER}_{\mathrm{abb}}\right)$ in 10 diabetic patients $(\bullet)$ and in 19 normal subjects $(x)$

Measurements in the diabetic patients are only compared directly to the measurements in each of the two seperate groups of normal subjects. The control group for plasma volume, TER $R_{\text {alb }}$ and extracellular fluid volume was well matched to the patients regarding age, sex and body size. The control group for colloid osmotic pressures was older than the patients (mean age 51 and 37 years, respectively). Noddeland [13], however, in a younger group of healthy volunteers (mean age 22 years, range 19-29 years), using the same method, found values for plasma and interstitial colloid osmotic pressure of the same magnitude as in our older control group $(26.9 \pm 4.1 / 28.6 \pm 3.4 \mathrm{mmHg}$ and $15.8 \pm 2.3$ / $15.8 \pm 2.7 \mathrm{mmHg}$, respectively). In our normal subjects there were no differences between females and males in plasma colloid osmotic pressure $(29.7 \pm 2.9$ and $28.6 \pm$ $3.5 \mathrm{mmHg}$, respectively) or in interstitial colloid osmotic pressure $(16.1 \pm 2.3$ and $15.7 \pm 3.0 \mathrm{mmHg}$, respectively).

Reduced interstitial colloid osmotic pressure has been reported in patients with nephrotic syndrome [23] and in heart failure [24] and has been described as an oedema-preventing mechanism [25]. In 1973, Poulsen [26] reported reduced values for subcutaneous interstitial fluid albumin concentration in long-term diabetes. Our findings of reduced interstitial colloid osmotic pressure in diabetic patients are in accordance with his results. None of our patients had nephropathy or heart failure.

The unexpected finding of increased interstitial fluid volume cannot be explained by nephropathy, heart failure or liver disease. It may fit with the clinical impression that long-term diabetic patients have a tendency to oedema which is not due to kidney, heart or liver disease. As there was no negative correlation between interstitial colloid osmotic pressure and interstitial fluid volume, the reduced pressure was probable not caused by simple dilution of interstitial proteins.

The values for $\mathrm{TER}_{\mathrm{alb}}$ in the diabetic and normal subjects confirm the findings of Parving et al. [4, 5]. The increased microvascular permeability to proteins would in itself tend to increase the interstitial protein mass and colloid osmotic pressure. The mechanism for reduction of interstitial colloid osmotic pressure is assumed to be increased net capillary filtration resulting in lymphatic wash-out of interstitial proteins [27]. The findings in our patients of reduced colloid osmotic pressure and increased TER $\mathrm{alb}_{\mathrm{ab}}$ indicate that the net capillary filtration of fluid is proportionally more increased than the filtration of proteins. The increased net capillary filtration of fluid can be due either to increased capillary filtration coefficient as described by Poulsen and Nielsen [9] or to increased hydrostatic capillary pressure. Even if our long-term diabetic patients did not have clinical signs or symptoms of cardiac failure, a subclinical depression of myocardial function, leading to increased hydrostatic capillary pressure, should not be ruled out $[24,28]$.

Increased transcapillary colloid osmotic gradient as found in our patients can, in a state of increased capillary permeability and filtration, be seen as a plasma volume-preserving factor and also as an oedema-preventing mechanism. The negative correlation between transcapillary colloid osmotic gradient and interstitial fluid volume may indicate that the increased gradient is operating as an oedema-preventing factor.

The increased capillary permeability in long-term diabetic patients leads to a new steady state. Our results indicate that this new balance is characterised by a tendency to increased interstitial fluid volume limited by an increase in the transcapillary colloid osmotic gradient. The activation in long-term diabetic patients of the oedema-preventing mechanism with reduced interstitial colloid osmotic pressure can perhaps explain the 
clinical impression that diabetic patients with fluid retention due to nephrotic syndrome or heart failure has an enhanced tendency to peripheral oedema.

\section{References}

1. Trap-Jensen $\mathbf{J}(1970)$ Increased capillary permeability to ${ }^{131}$ iodide and $\left({ }^{51} \mathrm{CR}\right) \mathrm{EDTA}$ in the exercising forearm of long-term diabetics. Clin Sci 39: 39-49

2. Trap-Jensen J, Alpert JS, del Rio G, Lassen NA (1967) Capillary diffusion capacity for sodium in skeletal muscle in long-term juvenile diabetes mellitus. Acta Med Scand suppl 476: 135-146

3. Leinonen H, Matikainen E, Juntunen J (1982) Permeability and morphology of skeletal muscle capillaries in Type 1 (insulin-dependent) diabetes mellitus. Diabetologia 22: 158-162

4. Parving HH, Munkgaard Rasmussen S (1973) Transcapillary escape rate of albumin and plasma volume in short- and long-term juvenile diabetics. Scand J Clin Lab Invest 32: 81-87

5. Parving HH, Rossing N (1973) Simulataneous determination of the transcapillary escape rate of albumin and $\mathrm{IgG}$ in the normal and long-term juvenile diabetic subjects. Scand J Clin Lab Invest 32: $239-244$

6. Bollinger A, Frey J, Jäger K, Furrer J, Seglias J, Siegenthaler W (1982) Patterns of diffusion through skin capillaries in patients with long-term diabetes. N Engl J Med 307: 1305-1310

7. Viberti GC (1983) Increased capillary permeability in diabetes mellitus und its relationship to microvascular angiopathy. Am $\mathbf{J}$ Med 30: 81-84

8. Alpert JS, Coffman JD, Balodimus MC, Koncz L, Soelder JS (1972) Capillary permeability and blood flow in skeletal muscle of patients with diabetes mellitus and genetic prediabetes. N Engl $\mathbf{J}$ Med 286: 454-460

9. Poulsen HL, Nielsen SL (1976) Water filtration of the forearm in short- and long-term diabetes mellitus. Diabetologia 12: 437-440

10. Aukland K, Johnson HM (1974) A colloid osmometer for small fluid samples. Acta Physiol Scand 90: 485 490

11. Aukland K, Fadnes HO (1973) Protein concentration of interstitial fluid collected from rat skin by wick method. Acta Physiol Scand 88: $350-358$

12. Johnson HM (1974) Measurement of colloid osmotic pressure of interstital fluid. Acta Physiol Scand 91: 142-144

13. Noddeland $H$ (1982) Colloid osmotic pressure of human subcutaneous interstitial fluid sampled by nylon wicks: evaluation of the method. Scand J clin Lab Invest 42: 123-130

14. Bauer JH (1976) Oral administration of radioactive sulfate to measure extracellular space in man. J Appl Physiol 40:648-650

15. Walser M, Seldin DW, Grollman A (1953) An evaluation of radio- sulfate for the determination of the volume of extracellular fluid in man and dogs. J Clin Invest 32: 299-311

16. McGrath BP, Tiller DJ, Horvath JS, Johnson JR (1976) Measurement of extracellular fluid volume in patients on maintenance hemodialysis. Kidney Int 9:57-59

17. Glasstone S (1956) Textbook of physical chemistry. Macmillan, London, pp 1259-1262

18. Parving HH, Gyntelberg F (1973) Transcapillary escape rate of albumin and plasma volume in essential hypertension. Circ Res 32 : 643-651

19. Parving HH (1975) Microvascular permeability to plasma proteins in hypertension and diabetes in man - on the pathogenesis of hypertensive and diabetic microangiopathy. Dan Med Bull 22: $217-233$

20. Aukland K, Nicolaysen G (1981) Interstitial fluid volume: local regulatory mechanisms. Physiol Rev 61: 556-643

21. Fadnes HO, Aukland K (1977) Protein concentration and colloid osmotic pressure of interstitial fluid collected by the wick technique. Analysis and evaluation of the method. Microvasc Res 14: 11-25

22. Bauer JH, Willis LR, Burt RW, Grim CE (1975) Volume studies II. Simultaneous determinations of plasma volume, red cell mass, extracellular fluid and total body water before and after volume expansion in dog and man. J Lab Clin Med 86: 1009-1017.

23. Noddeland H, Riisnes SM, Fadnes HO (1982) Interstitial fluid colloid osmotic and hydrostatic pressure in subcutaneous tissue of patients with nephrotic syndrome. Scand J Clin Lab Invest 42: 139-146

24. Noddeland H, Omvik P, Lund-Johansen P, Ofstad J, Aukland K (1984) Interstitial colloid osmotic pressures in human subcutaneous tissue during early stages of heart failure. Clin Physiol 4: 283-297

25. Aukland K (1973) Autoregulation of interstitial fluid volume. Edema-preventing mechanisms Scand J Clin Lab Invest 31: 247-254

26. Poulsen HL (1973) Subcutaneous interstitial fluid albumin concentration in long-term diabetes mellitus. Scand J Clin Lab Invest 32: $167-173$

27. Wiederhielm CA (1979) Dynamics of capillary fluid exchange: A nonlinear computer simulation. Microvasc Res 18: 48-82

28. Hamby RJ, Zoneraich S, Sherman L (1974) Diabetic cardiomyopathy. JAMA 229: 1749-1754

Received: 5 September 1984

and in revised form: 4 March 1985

Dr. Per Fauchald

Medical Department B

Rikshospitalet

Oslo 1

Norway 